\title{
Intraoperative complications after total laparoscopic hysterectomy: a retrospective study in training institute
}

\author{
Richa Patel*, Arun Moray
}

Department of Obstetrics and Gynecology, SBHGMC, Dhule, Maharashtra, India

Received: 16 January 2019

Accepted: 08 February 2019

\author{
*Correspondence: \\ Dr. Richa Patel, \\ E-mail: rich174364@gmail.com
}

Copyright: (C) the author(s), publisher and licensee Medip Academy. This is an open-access article distributed under the terms of the Creative Commons Attribution Non-Commercial License, which permits unrestricted non-commercial use, distribution, and reproduction in any medium, provided the original work is properly cited.

\begin{abstract}
Background: Hysterectomy is a common gynecological surgery performed in premenopausal and menopausal age group. Different types of approaches are there with their advantages and disadvantages, it is mainly indicated for noncancerous conditions. Till today three different surgical approaches to hysterectomy are available: vaginal, abdominal and laparoscopic. TLH has been reported to result in shorter procedure durations, lower blood losses, and shorter hospital stays.

Methods: This is a retrospective case study, was carried out over a 5-year period in a tertiary care institute. Study done on patients attending gynecology OPD at our tertiary care institute during the period since September 2013 to September 2018 .

Results: In present study out of 646 endoscopic hysterectomies in last five years authors studied 420 Total Laparoscopic Hysterectomies. Conversion to open surgery rate was 0.3\%. Mean age was 49.26 years (SD-9.53), Performed for various indications with various BMI patients. Mean surgical duration was 116.55 minutes with SD 26.27. Major complication rate was $2.85 \%$ with 2 cases of bowel injuries and 3 cases of urological injuries.

Conclusions: Total laparoscopic hysterectomy appears safe and effective approach for variety of indications with minimal morbidity. Beneficial for all age group all nulliparous /multiparous patients as well as obese patients. With the knowledge of all complication and its prevention, maximum surgeons can give benefit of advantages of total laparoscopic hysterectomy to all women. More and more randomized clinical trials will motivate surgeons for this approach.
\end{abstract}

Keywords: Hysterectomy, Intraoperative complications, TLH

\section{INTRODUCTION}

Hysterectomy is a common gynecological surgery performed in premenopausal and menopausal age group. Different types of approaches are there with their advantages and disadvantages, it is mainly indicated for noncancerous conditions. ${ }^{1}$ Till today three different surgical approaches to hysterectomy are available: vaginal, abdominal and laparoscopic. Laparoscopic Hysterectomy the histological origin of endoscopy can be traced back to the Greek school of Kos led by
Hippocrates (460-375 BC), who described the use of rectal and primitive vaginal speculae. ${ }^{2}$ The forerunner of the optical system of modern endoscopes was the cystoscope, developed by Nitze of Germany in the 19th century. ${ }^{2}$ In 1901, Georg Kelling of Dresden introduced a cystoscope into a dog's abdominal cavity, thus performing the first laparoscopy. ${ }^{3}$ The first human laparoscopy was performed by Hans Christian Jacobaeus of Stockholm in 1911, by using Pneumoperitoneum and the Nitzecysto scope most frequently performed gynecological operations. ${ }^{3-5}$ It was Raoul Palmer of 
France who popularized gynecological laparoscopy in the 1940's and who is considered to be the father of modern gynecological laparoscopy Kurt Semm in Germany first described a technique for laparoscopic assistance in vaginal hysterectomy, in 1984.The adnexa were separated laparoscopically in order to simplify vaginal hysterectomy. This was later called laparoscopically assisted vaginal hysterectomy. ${ }^{3-5}$

In 1988, Harry Reich performed the first total laparoscopic hysterectomy in Pennsylvania. The ligaments and uterine vessels were coagulated with bipolar forceps and cut with scissors. The vagina was opened and closed laparoscopically. The total operating time was 180 minutes, the uterus weighed $230 \mathrm{~g}$ and the patient was discharged on the fourth postoperative day. ${ }^{6}$ Reich published his article the following year and demonstrated his technique worldwide. Since the first case published by Reich and co-workers, an increasing number of authors have reported their techniques. The total laparoscopic hysterectomy (TLH) is a laparoscopic hysterectomy in which all of the surgical dissections, ligations, and sutures are completed entirely through the trocars, including the closure of the vagina. ${ }^{7}$ TLH has been reported to result in shorter procedure durations, lower blood losses, and shorter hospital stays. ${ }^{8,9}$

\section{METHODS}

This is a retrospective case study was carried out over a 5 -year period in a tertiary care institute. Study done on patients attending gynecology OPD at our tertiary care institute during the period since September 2013 to September2018. Various types of hysterectomy performed in this duration on patients attending gynecological OPD of our institute. Patients are screened and operative procedure decided on basis of indications and surgeon's skill. Data about preoperative and intraoperative findings of patients who underwent total laparoscopic hysterectomy collected.

\section{Procedure followed for TLH}

The position given to patient was modified lithotomy position with hips extended, in a 40-degree angle Trendelenburg position. Shoulder bolsters prevent slippage up the table, and the arms are padded and tucked by the side.

After the examination under anesthesia, a uterine manipulator is inserted. Veress needle insertion and pneumoperitoneum formation done in all cases. Primary trocar is inserted at supraumbilical site.

After laparoscopic evaluation of uterus and adnexa, with bipolar cautery occlusion of the proximal fallopian tubes. After visual inspection of the ureter at the pelvic brim, the infundibulo pelvic ligament, or, utero-ovarian ligament iscoagulated and incised with amonopolar cautery. Immediately after the round ligament is incised, the uterus, on the uterine manipulator, is pushed cephalad to recreate the "traction counter-traction" concept of open surgical dissection of the lower uterine segment. This elevates the uterine arteries along the lower cervix away from the ureters. A bladder flap is incised, and the anterior cervical fascia is exposed with blunt dissection off of the cervix broadly below the cervicovaginal margin. The uterine arteries are coagulated with a bipolar cautery at the mid lower cervical length, and then incised with the monopolar cautery. The uterine arteries are pushed downward to expose the cardinal ligament fibers attaching the arteries to the cylindrical cervical fascia; then the cardinal fibers are incised posteriorly to the uterosacral ligaments, and inferiorly, identifying the cervicovaginal margin as the lowest limit of dissection. The cervicovaginal margin is laparoscopically included.

\section{RESULTS}

In last five years at our training institute total 646 laparoscopic hysterectomy performed out of which, 222 were laparoscopic assisted vaginal hysterectomy, 4 turned into open laparotomy and 420 were total laparoscopic hysterectomy. Out of four laparotomy, two were due to unable to catch bleeder through laparoscope, one due to bowel injury because of dense adhesion and one was due to pseudo broad ligament myoma. Thus, the conversation of laparoscopic rate was $0.3 \%$. In present study out of 420 cases, $16.66 \%$ were between age group 36 to 40 years, $22.38 \%$ were between age group 41 to 45 years, $25.24 \%$ were between age group 46 to 50 years, $22.38 \%$ were between age group 51 to 55 year and $13.34 \%$ were above 55 years.

It was observed that maximum number of cases were reported between age group 46 to 50 years with $25.24 \%$ (106), while minimum number of cases were reported above age 55 years with $13.34 \%$ (56). Mean of the above grouped data is 49.26. Standard deviation of the above grouped data is 9.53 (Table 1).

Table 1: Age wise distribution of patients.

\begin{tabular}{|l|l|l|}
\hline A ge group (years) & No. of patients & Percentage \\
\hline 36 to 40 & 70 & 16.66 \\
\hline 40 to 45 & 94 & 22.38 \\
\hline 45 to 50 & 106 & 25.24 \\
\hline 55 to 55 & 94 & 22.38 \\
\hline$>55$ & 56 & 13.34 \\
\hline Total & 420 & 100 \\
\hline
\end{tabular}

In present study out of 419 cases, $3.8 \%$ had parity 0 , $33.09 \%$ had parity $1,45.25 \%$ had parity $2,17.86 \%$ had parity 3 and above. It was observed that maximum number of cases were reported for parity 2 with $45.34 \%$ (190), while minimum number of cases were reported for parity 0 with $3.58 \%$ (15).

Mean of the above grouped data is 1.95. Standard deviation of the above grouped data is 1.09 (Table 2). 
Table 2: Distribution of patients according to parity.

\begin{tabular}{|l|l|l|}
\hline Parity & No. of patients & Percentage \\
\hline 0 & 16 & 3.8 \\
\hline 1 & 139 & 33.09 \\
\hline 2 & 190 & 45.25 \\
\hline$>3$ & 75 & 17.86 \\
\hline Total & 420 & 100 \\
\hline
\end{tabular}

In present study out of 420 cases, $28.10 \%$ had indications of DUB, $20 \%$ had indications of fibroid, $15.23 \%$ had indications of PID, $8.57 \%$ had indications of adenomyosis, $12.38 \%$ has indications of abnormal pap smear in chronic and $15.72 \%$ had indications of cervicitis.

It was observed that maximum number of indications were reported for DUB with $28.10 \%$ (118), while minimum number of indications were reported for adenomyosis with $3.58 \%$ (15). Mean of the above grouped data is 70. Standard deviation of the above grouped data is 25.92 .

Commonest indication was dysfunctional uterine bleeding followed by fibroid, PID adenomyosis and chronic cervicitis. Fibroid were of different sizes and locations with maximum size $18 \times 14 \mathrm{~cm}$, TLH done for all different indications hence TLH can be performed for variety of lesions of uterus and size /site is not a contraindication for TLH. Age, Parity and BMI was not significant factor for analysing surgical duration and blood loss (Table 3).

Table 3: Analysis of indications of hysterectomy.

\begin{tabular}{|l|l|l|}
\hline Indications & $\begin{array}{l}\text { No. of } \\
\text { patients }\end{array}$ & Percentage \\
\hline DUB & 118 & 28.10 \\
\hline Fibroid & 84 & 20 \\
\hline PID & 64 & 15.23 \\
\hline Adenomyosis & 36 & 8.57 \\
\hline Abnormal pap smear in chronic & 52 & 12.38 \\
\hline Cervicitis & 66 & 15.72 \\
\hline Total & 420 & 100 \\
\hline
\end{tabular}

Surgical duration was calculated from surgical records cross verified with anaesthesia records. Patients required prolong time due to anaesthesia complications or associated surgical procedure were excluded, the mean surgical time was 116.55 minutes $(\mathrm{SD}=26.27$ with range from 50 to 190 minutes) over $2 / 3$ of surgeries were completed in 100 minutes or less.

In present study out of 420 cases, $16.66 \%$ had surgical duration less than 90 minutes, $43.81 \%$ had surgical duration between 91 to 120 minutes, $32.39 \%$ had surgical duration between 121 to 150 minutes, $5.95 \%$ had surgical duration between 151 to 180 minutes and $1.19 \%$ has surgical duration greater than 181 minutes.
It was observed that maximum number of surgical durations were reported for duration 121-150 minutes with $32.39 \%$ (136), while minimum number surgical duration were reported for duration greater than 181 minutes with $1.19 \%$ (5). Mean of the above grouped data is 116.55. Standard deviation of the above grouped data is 26.27 (Table 4).

\section{Table 4: Surgical duration.}

\begin{tabular}{|l|l|l|}
\hline Surgical duration & No. of patients & Percentage \\
\hline$\geq 90$ minutes & 70 & 16.66 \\
\hline $91-120$ minutes & 184 & 43.81 \\
\hline $121-150$ minutes & 136 & 32.39 \\
\hline $151-180$ minutes & 25 & 5.95 \\
\hline$>181$ minutes & 5 & 1.19 \\
\hline Total & 420 & 100 \\
\hline
\end{tabular}

Bloss was estimated from the changing vitals during intraoperative period requiring quatery and post-operative blood transfusion. More than fifty prevent patients had less than $60-80 \mathrm{ml}$ of blood loss. Only three patients required post op blood transfusion mostly due to preoperative status.

In present study out of 420 cases, $34.53 \%$ had amount of blood loss less than $60 \mathrm{ml}, 30.95 \%$ had amount of blood loss between 61 to $80 \mathrm{ml}, 26.67 \%$ had amount of blood loss between 81 to $150 \mathrm{ml}, 7.14 \%$ had amount of blood loss greater than $151 \mathrm{ml}$ and $0.71 \%$ had blood transfusion required.

It was observed that maximum amount of patients had blood loss reported was less than $60 \mathrm{ml}$ with $34.53 \%$ (145), while minimum amount of patients had blood loss reported was greater than $151 \mathrm{ml}$ with $7.14 \%$ (30). 0.71 $\%$ (3) patients were required to transfuse blood.

Mean of the above grouped data is 84.75. Standard deviation of the above grouped data is 34.93 (Table 5).

Table 5: Intraoperative blood loss.

\begin{tabular}{|l|l|l|}
\hline Amount of blood loss in ml & $\begin{array}{l}\text { No. of } \\
\text { patients }\end{array}$ & \begin{tabular}{l} 
Percentage \\
\hline$<60 \mathrm{ml}$
\end{tabular} \\
\hline $61-80 \mathrm{ml}$ & 145 & 34.53 \\
\hline $81-150 \mathrm{ml}$ & 130 & 30.95 \\
\hline$>151 \mathrm{ml}$ & 112 & 26.67 \\
\hline Blood transfusions required & 30 & 7.14 \\
\hline Total & 3 & 0.71 \\
\hline
\end{tabular}

In present study out of 420 cases, $2.85 \%$ (12) cases had major intraoperative complications. $33.33 \%$ (4) of 12 cases had Hemorrhage, $16.67 \%$ (2) of 12 cases had Bowel injuries, $25 \%$ (3) of 12 cases had Urological injuries and $25 \%$ (3) cases of 12 cases had Anesthesia complications. It was observed that maximum number of complications was reported for Hemorrhage with $33.33 \%$ 
(4), while minimum number of complications was reported for Bowel injuries with $16.67 \%$ (2).

Mean of the above grouped data is 3. Standard deviation of the above grouped data is 2.23 (Table 6).

Table 6: Distribution of patients according to major interaoperative complications.

\begin{tabular}{|l|l|l|}
\hline Complications & $\begin{array}{l}\text { No. of } \\
\text { patients }\end{array}$ & Percentage \\
\hline Hamorrhage & 4 & 33.33 \\
\hline Bowel injuries & 2 & 16.67 \\
\hline Urological injuries & 3 & 25 \\
\hline Anesthesia complications & 3 & 25 \\
\hline Total & 12 & 100 \\
\hline
\end{tabular}

Along with above major complications 40 patients have few minor complications like nausea vomiting, chest discomfort, misplace of suture material, wrong passage of veress needle or trocar while insertion which were immediately tracked by seniors, so over all 52 patients $(12.3 \%)$ had intraoperative complications. Out of 12 major complications 5 required reoperation to overcome it. In present study out of 420 cases, $9.52 \%$ (40) cases had minor complications. $35 \%$ (14) of 40 cases had Nausea, $12.5 \%$ (5) of 40 cases had Vomiting, 30\% (12) of 40 cases had Chest discomfort, $7.5 \%$ (3) of 40 cases had Misplace of suture material and $15 \%$ (6) cases of 40 cases had Wrong passage of verses needle or trocar. It was observed that maximum number of complications was reported for Nausea with 35\% (14), while minimum number of complications was reported for Misplace of suture material with $7.5 \%$ (3). Mean of the above grouped data is 8 . Standard deviation of the above grouped data is 5.55 (Table 7).

Table 7: Distribution of patients according to minor interaoperative complications.

\begin{tabular}{|l|l|l|}
\hline Complications & $\begin{array}{l}\text { No. of } \\
\text { patients }\end{array}$ & Percentage \\
\hline Nausea & 14 & 35 \\
\hline Vomiting & 5 & 12.5 \\
\hline $\begin{array}{l}\text { Chest discomfort } \\
\text { Misplace of suture material }\end{array}$ & 12 & 30 \\
\hline $\begin{array}{l}\text { Wrong passage of verses } \\
\text { needle or trocar }\end{array}$ & 6 & 7.5 \\
\hline Total & 40 & 15 \\
\hline
\end{tabular}

\section{DISCUSSION}

Age, BMI descent and size of uterus doesn't affect output of total laparoscopic hysterectomy. It can be done with same results in all parity women, as time duration for surgery is concerned it is slightly more than abdominal hysterectomy but almost similar to LAVH and NDVH. ${ }^{10,11}$ Expertise definitely reduce this difference as in present study also surgery done by seniors having more than three years of experience perform total laparoscopic hysterectomy in less time.

Following are few complications which should be kept in mind to avoid by beginners. In present study the major complications rate was of $2.8 \%$ and minor complication rates $12.3 \%$ which is less in compare to other case studies. Katherine A. O'Hanlon, major complication rate of $4.5 \%$ in this series are comparable to rates in other TLH series. ${ }^{13-16}$ Hoffman et al (14)had a total and major complication rate of $10 \%$ and $5.6 \%$, while Heinberg et al had a major complication rate of $14.4 \%$, and Chapron reported complications in $10 \% .{ }^{15,16}$

\section{Hemorrhagic events}

Hemorrhage seen retroperitoneal and intraabdominally, vaginally in patients, $1-2 \%$ respectively, as observed in other series. Hemorrhage noticed in shifting of patient or in recovery room taken immediate to the operating room for additional suture placement vaginally. Using at least 3 figure-of-eight (technically spiral)sutures along the vaginal apex seems essential, even when there is good homeostasis of the cuff edge.

Of the 4 patients with abdominal or retroperitoneal hemorrhage, two were managed expectantly because they maintained with normal vital signs. One developed hypotension during the procedure required transfusion and evacuation of hematoma.

\section{Intestinal injuries}

Two bowel injuries occurred in study, both were recognized immediately and repaired. One patient had slippage of the trochar outside of the abdominal cavity, with reinsertion performed by fellow students without direct observation, through the bowel wall, requiring a figure-of-eight imbrications of both sites with 3-0 polygalactic acid suture.

\section{Urologic injuries}

Out of all three patients had a urological injury, with one requiring reoperation, one cystoscopic ureteral stent placements and one laparotomy for closure of bladder fistula.

\section{CONCLUSION}

Total laparoscopic hysterectomy appears safe and effective approach for variety of indications with minimal morbidity. Beneficial for all age group all nulliparous /multiparous patients as well as obese patients. With the knowledge of all complication and its prevention, maximum surgeons can give benefit of advantages of total laparoscopic hysterectomy to all women. More and more randomized clinical trials will motivate surgeons for this approach. 


\section{ACKNOWLEDGMENTS}

Authors would like to thank Dean, SBHGMC, HOD Department of Anaesthesia and all the staff at Department of Obstetrics and Gynecology, SBHGMC, Dhule, Maharashtra, India.

Funding: No funding sources

Conflict of interest: None declared

Ethical approval: The study was approved by the Institutional Ethics Committee

\section{REFERENCES}

1. Baskett TF. Hysterectomy: evolution and trends. Best Pract Res Clin Obstet Gynaecol 2005; 19(3):295-305.

2. Lau WY, Leow CK, Li AK. History of Endoscopicand Laparoscopic surgery. World J Surg 1997; 21(4):444-53.

3. Himal HS. Minimally invasive (laparoscopic) surgery. Surg Endosc 2002; 16(12):1647-52.

4. Clayton RD. Hysterectomy. Best Pract Res Clin Obstet Gynaecol 2006;20:73-87.

5. H Rkki-Sirén P. Laparoscopic hysterectomy. Outcomeand complications in Finland. [doctoral thesis]. Helsinki: Medical Faculty University of Helsinki;1999.

6. Reich H, DeCaprio J, McGlynn F. Laparoscopichysterectomy. J Gynecol Surg 1989; 5(2):213-6

7. Nezhat C, Nezhat F, Admon D, Nezhat AA. Proposed classification of hysterectomies involving laparoscopy. J Am Assoc Gynecol Laparosc. 1995;2(4):427-9.

8. Lee PI, Lee YT, Lee SH, Chang YK. Advantages of total laparoscopic hysterectomy. J Am Assoc Gynecol Laparosc.1996;3(4):S24-5.
9. Hasson HM, Rotman C, Rana N, Asakura H. Experience with laparoscopic hysterectomy. J Am Assoc Gynecol Laparosc.1993;1(1):1-11.

10. O’Hanlan KA, Huang GS, Lopez L, Garnier AC. Total laparoscopic hysterectomy for oncological indications with outcomes stratified by age. Gynecol Oncol.2004;95(1):196-203

11. O’Hanlan KA, Huang GS, Lopez L, Garnier AC. Selective incorporation of total laparoscopic hysterectomy for adnexal pathology and body mass index.Gynecol Oncol.2004;93(1):137-43.

12. Johnson N, Barlow D, Lethaby A, Tavender E, Curr E, Garry R. Surgical approach to hysterectomy for benign gynaecological disease. Cochrane Database SystRev.2005(1):CD003677.

13. O'Hanlan AK, Dibble SL, Garnier AC, Reuland LM, J Soc Laparo endoscopic Surg JSLS (2007)11:45-53.

14. Hoffman CP, Kennedy J, Borschel L, Burchette R, Kidd A. Laparoscopic hysterectomy: the Kaiser Permanente San Diego experience. J Minimal Invas Gynecol. 2005;12(1):16-24.

15. Chapron C, Dubuisson JB, Ansquer Y, Fernandez B. Totalhysterectomy for benign pathologies. Laparoscopic surgery does not seem to increase the risk of complications. J Gynecol Obstet Biol Reprod (Paris).1998;27(1):55-61.

16. Heinberg EM, Crawford BL, Weitzen SH, Bonilla DJ. Total laparoscopic hysterectomy in obese versus nonobese patients. Obstet Gynecol. 2004;103(4):674-80.

Cite this article as: Patel R, Moray A. Intraoperative complications after total laparoscopic hysterectomy: a retrospective study in training institute. Int $\mathbf{J}$ Reprod Contracept Obstet Gynecol 2019;8:835-9. 